\title{
ChemComm
}

\section{Metal-organic frameworks as potential shock absorbers: the case of the highly flexible MIL-53(Al) $\dagger$}

50, 9462

Received 20th May 2014,

Accepted 3rd July 2014

DOI: $10.1039 / c 4 c c 03853 c$

www.rsc.org/chemcomm

\author{
Pascal G. Yot, ${ }^{a}$ Zoubeyr Boudene, ${ }^{a}$ Jasmine Macia, ${ }^{a}$ Dominique Granier, \\ Louis Vanduyfhuys, ${ }^{\mathrm{b}}$ Toon Verstraelen, ${ }^{\mathrm{b}}$ Veronique Van Speybroeck, \\ Thomas Devic, ${ }^{c}$ Christian Serre, ${ }^{c}$ Gérard Férey, ${ }^{c}$ Norbert Stock ${ }^{d}$ and \\ Guillaume Maurin ${ }^{\mathrm{a}}$
}

The mechanical energy absorption ability of the highly flexible MIL-53(Al) MOF material was explored using a combination of experiments and molecular simulations. A pressure-induced transition between the large pore and the closed pore forms of this solid was revealed to be irreversible and associated with a relatively large energy absorption capacity. Both features make MIL-53(Al) the first potential MOF candidate for further use as a shock absorber.

Mesoporous hydrophobic silica solids have been envisaged so far as promising materials for energy storage applications due to the relatively high energies absorbed by them during water intrusionextrusion cycles. ${ }^{1-3}$ Crystalline hybrid solids, known as metalorganic frameworks (MOFs) are one of the latest classes of porous solids. Besides their interest for a broad range of applications including gas separation, ${ }^{4}$ catalysis ${ }^{5}$ and biomedicine, ${ }^{6}$ more recently these materials have attracted growing interest for their potential in the field of mechanical energy storage. ${ }^{7-9}$ In order to maximize the energy absorbed during 1 cycle of compressiondecompression $(W=P \times \Delta V)$, MOFs combining large unit cell variations and high transition pressures should be considered. In this context, the highly flexible microporous MIL-53(Cr,In)/ MIL-47( $\left.\mathrm{V}^{\mathrm{IV}}\right)$ (MIL stands for Materials of Institut Lavoisier) appear appealing. These solids, built up from $\mu_{2}-\mathrm{OH} / \mathrm{O}$ corner-sharing chains of metal octahedra linked by terephthalate ligands to define diamond-shaped channels, were shown to endure a structural switch from a large pore (LP) to a closed pore (CP)

\footnotetext{
${ }^{a}$ Institut Charles Gerhardt Montpellier, Université Montpellier 2,

Place Eugène Bataillon, 34095 Montpellier cedex 05, France.

E-mail: pascal.yot@univ-montp2.fr; Fax: +33467144290

${ }^{b}$ Center for Molecular Modeling, Ghent University, Technologiepark 903,

B-9052 Zwijnaarde, Belgium

${ }^{c}$ Institut Lavoisier Versailles, Université de Versailles St-Quentin,

45, avenue des Etats-Unis, 78035 Versailles cedex, France

${ }^{d}$ Institute für Anorganische Chemie, Christian-Albrechts-Universität,

Max-EythStraße2, D 24118 Kiel, Germany

$\dagger$ Electronic supplementary information (ESI) available: Experimental procedure, $\mathrm{X}$-ray diffraction, the Raman scattering procedure and molecular simulations. CCDC 1004911 and 1004912. For ESI and crystallographic data in CIF or other electronic format see DOI: 10.1039/c4cc03853c
}

corresponding to a unit cell volume variation up to $38 \%$ at moderate applied pressures (from 55 to $125 \mathrm{MPa}){ }^{10-12}$

In all cases, the structural transformation is reversible and associated with a relatively large hysteresis, which makes these materials attractive for energy absorption applications in the form of nano-dampers. More recently, confining polar molecules into the pores of MIL-53(Cr) was predicted to induce an irreversible pressure-induced structural response. ${ }^{13}$ This preliminary computational study emphasized that this series of materials can also be attractive for shock absorber applications, i.e. devices able to absorb the mechanical energy during the compression without any further release. The resulting energy storage capacities of 12 and $33 \mathrm{~J} \mathrm{~g}^{-1}$ during one cycle of compression-decompression for MIL-53(Cr) and MIL-47 $\left(\mathrm{V}^{\mathrm{IV}}\right)$ respectively were revealed to be higher than the ones of the mesoporous hydrophobic materials $\left(\sim 4-10 \mathrm{~J} \mathrm{~g}^{-1}\right) \cdot^{1-3}$

The breathing behavior of the series of MIL-53s, either induced by guest adsorption or temperature, was found to be modulated by the nature of the metal center. ${ }^{14-16}$ Inspired by this welldocumented literature, the MIL-53 in its Al-version ${ }^{17}$ was selected to probe the impact of the metal center on the mechanical performance of this family of materials. Complementary experiments including mercury intrusion, X-ray powder diffraction and Raman scattering were coupled to provide the first experimental evidence that such a solid can be promising as a nano-shock absorber. Molecular dynamics simulations based on an ab initio flexible force-field were also performed to gain insight into the microscopic mechanism at the origin of the irreversible nature of the structural transition between a large pore (LP) and a closed pore (CP) forms once an external pressure is applied (Fig. 1).

Mercury porosimetry experiments were first conducted on the MIL-53(Al) sample which was preliminarily activated at $250{ }^{\circ} \mathrm{C}$ under secondary vacuum for 8 hours. Such a treatment ensures that the solid is initially present in its LP form as confirmed by the X-ray powder diffraction (XRPD) analysis (Table 1) (ESI, † Fig. S4).

Fig. 2 shows the evolution of the cumulative volume of intruded mercury as a function of the applied pressure after two intrusionextrusion (compression-decompression) cycles. Two regions can be distinguished: (i) below $2 \mathrm{MPa}$ where the intruded $\mathrm{Hg}$ corresponds 
(a)

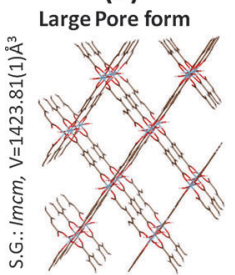

(b)

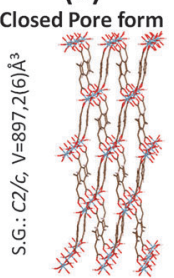

(c)

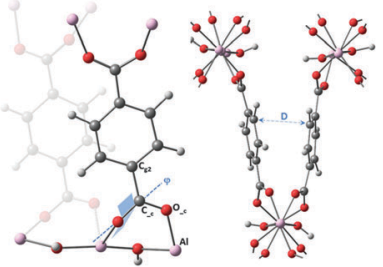

Fig. 1 Schematic representation of the pressure induced phase transition of the MIL-53(Al) between the large pore form (a) and the closed pore form (b). (c) and (d) provide an illustration of the $\mathrm{Al}-\mathrm{O}_{\mathrm{c}}-\mathrm{C}_{\mathrm{c}}-\mathrm{C}_{\mathrm{g} 2}$ dihedral angle $\varphi$ and the mean distance $D$ separating the phenyl rings respectively.

Table 1 Unit cell parameters and volume of the different forms of the MIL-53(Al) before (large pore form: LP) and after (closed pore form: CP) compression experiment and their comparison with reference data from the work of Liu et al. ${ }^{15}$

\begin{tabular}{lllll}
\hline Form & \multicolumn{2}{l}{ Large pore } & Closed pore & Large pore \\
\hline S.G. & Narrow pore $^{15}$ \\
$a(\AA)$ & Imcm & $C 2 / c$ & Imcm & $C 2 / c$ \\
$b(\AA)$ & $16.7322(1)$ & $19.633(1)$ & $16.744(2)$ & $20.824(1)$ \\
$c(\AA)^{15}$ & $12.8357(7)$ & $7.160(1)$ & $12.847(2)$ & $6.6067(5)$ \\
$\beta\left({ }^{\circ}\right)$ & $6.6295(2)$ & $6.559(1)$ & $6.6384(5)$ & $6.871(1)$ \\
$V\left(\AA^{3}\right)$ & - & $104.70(1)$ & - & $113.948(6)$ \\
Temperature (K) & $1423.8(1)$ & $897.2(6)$ & $1427.5(3)$ & $863.9(2)$ \\
& & 298 & 295 & 77
\end{tabular}

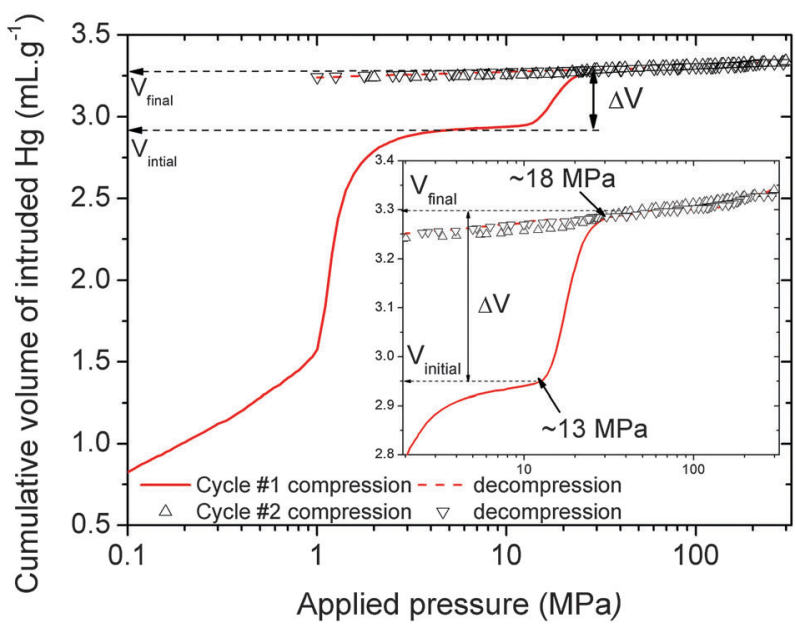

Fig. 2 Cumulative volume of intruded mercury in two intrusion-extrusion cycles as a function of the applied pressure obtained for the MIL-53(Al) sample $\left(V_{\text {intial }}\right.$ and $V_{\text {final }}$ are the volumes of mercury intruded before and after the contraction of the solid respectively).

to the compaction of the powder and the filling of the interparticular porosity, which ensures isostatic conditions around the particles and (ii) a sudden increase of the volume of $\mathrm{Hg}$ intruded between 13 and $18 \mathrm{MPa}$.

This step is assigned to a contraction of the solid, and not to a penetration into its pore according to the Washburn equation (see $\mathrm{ESI} \dagger$ ), and would correspond to an intrusion of a pore size of $70 \mathrm{~nm}$ which considerably exceeds that of the microporous MIL-53(Al) solid $(0.85 \mathrm{~nm})$. By analogy with the conclusions previously drawn for other MIL-53 analogues, ${ }^{10-12}$ this volume variation can be associated with a contraction of the initial LP form (Fig. 1). The relative volume variation $\left(V_{\text {final }}-V_{\text {initial }}\right) / V_{\text {initial }}$ is close to $35 \%$ which would lead to a contracted form with a unit cell volume of $\sim 920 \AA^{3}$ considering a cell volume of $1424 \AA^{3}$ for the initial LP phase. Both profile and magnitude of the intruded $\mathrm{Hg}$ volume recorded in the first compression step are similar to the ones previously evidenced for the isostructural MIL-53(Cr) (32\%) and MIL-47( $\left.\mathrm{V}^{\mathrm{IV}}\right)(38 \%){ }^{10-12}$

This result drastically deviates from the very recent study reported by Gascon $e t$ al. which surprisingly shows a gradual decrease of the unit cell volume for the LP form of MIL-53(Al), the closed pore version being only attained at a very high pressure $(6 \mathrm{GPa}) .{ }^{18}$ One can however notice that the so-obtained transition pressure ( 13-18 MPa) is significantly lower than the ones obtained for MIL53(Cr) and MIL-47( $\left(\mathrm{V}^{\mathrm{V} V}\right)$ (53 MPa and 85-125 MPa respectively). This emphasizes a higher compressibility of the Al-solid and results in the early onset of the structural contraction. This is supported by a much lower estimated bulk modulus for the LP form of MIL-53(Al) at room temperature, $K_{\mathrm{LP}} \sim 0.35 \mathrm{GPa}$ (see $\mathrm{ESI} \dagger$ ), $v$ s. the ones previously reported for the $\mathrm{Cr}$ version (1.8 to $2.0 \mathrm{GPa}$ ). ${ }^{19,20}$ More interestingly, while MIL-53(Cr) and MIL-47 $\left(\mathrm{V}^{\mathrm{IV}}\right)$ showed a reversible structural transition in the presence of a hysteresis, here Fig. 2 suggests that upon decompression, the Al-version remains in the contracted CP form. This holds also true for the second compression-decompression cycle where no variation of the intruded $\mathrm{Hg}$ volume was detected. To confirm such findings, XRPD analysis was carried out on the powder obtained at the end of the porosimetry experiments. The new phase was successfully indexed in the space group $C 2 / c$ (Fig. S5, ESI $\dagger$ ) with a cell volume $V_{\mathrm{CP}} \sim 897 \AA^{3}$ (Table 1) which agrees well with the value estimated from the mercury intrusion $\left(920 \AA^{3}\right)$. Furthermore, XRPD indicates a minor fraction of the LP form detected, which results from a kinetic reopening at a larger time scale (see ESI $\dagger$ ). This structure is similar to the one previously reported by Liu et $a l^{15}$ for the same solid detected at low temperature $\left(863.9 \AA^{3}\right)$ and labeled as the narrow pore (NP) form (see Table 1). The pressure induced LP-CP structural transformation for MIL-53(Al) was also evidenced by Raman scattering experiments which showed a downshift of the $\nu_{\text {sym }}(\mathrm{COO})$ band (see ESI, $\dagger$ Fig. S6) under compression, characteristic of a transition towards a more contracted structure. ${ }^{11}$ The XRPD experiments further confirmed the irreversible nature of the transition, which differs from its reversible transformation observed upon thermal stimuli. ${ }^{15}$

To gain further insight into the irreversible structural switching of this solid under compression-decompression, molecular dynamics (MD) simulations were performed in the $\mathrm{N} \sigma \mathrm{T}$ ensemble to follow the size and shape modifications of the MIL-53(Al) framework at $300 \mathrm{~K}$ under variable applied pressures of up to $200 \mathrm{MPa}$. These calculations were based on the $a b$ initio force field developed recently by some of us (see $\mathrm{ESI} \dagger$ ). ${ }^{21}$ The simulated evolution of the unit cell volume as a function of the pressure is reported in Fig. 3. It evidenced that the MIL-53(Al) initially in its LP form undergoes a sudden decrease of its cell volume for an applied pressure of $19 \mathrm{MPa}$ which matches well the range of values corresponding to the step observed in the intrusion curve (13-18 MPa). Further, the resulting CP form possesses a unit cell volume $\left(\sim 820 \AA^{3}\right)$ only slightly lower than the one obtained using XRPD data 


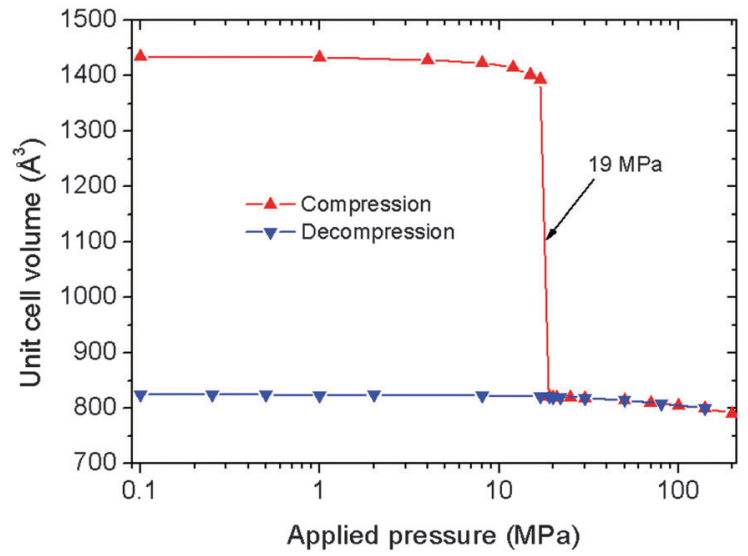

Fig. 3 MD simulated evolution of the unit cell volume of MIL-53(Al) at $300 \mathrm{~K}$ as a function of the applied pressure.

$\left(\sim 897.2 \AA^{3}\right)$. Interestingly, in contrast to our previous computational findings on MIL-53(Cr) and MIL- $47\left(\mathrm{~V}^{\mathrm{IV}}\right),{ }^{6,7}$ the Al-version remains in its $\mathrm{CP}$ form once the applied pressure is released. This is fully consistent with the irreversible nature of the structural transition as experimentally revealed.

A deeper analysis of the geometrical features of the LP and CP forms of MIL-53(Al) was further undertaken. Similarly to the Cr- and V-analogues, the structural shrinkage of the unit cell when LP switches to CP occurs via a rotation of the linker about the $\mathrm{O}_{\mathrm{c}}-\mathrm{O}_{\mathrm{c}}$ axis as detected by a significant change of the $\mathrm{M}-\mathrm{O}_{\mathrm{c}}{ }^{-}$ $\mathrm{C}_{\mathrm{c}}-\mathrm{C}_{\mathrm{g} 2}\left(\mathrm{M}=\mathrm{Al}, \mathrm{Cr}, \mathrm{V}^{\mathrm{IV}}\right)$ dihedral angle $(\varphi)$ and its corresponding intramolecular energy (Fig. 1 and Fig. S7, ESI $\dagger$ ). Fig. S8 (ESI $\dagger$ ) shows that while in the LP form the distribution of $\varphi$ is similar to those in MIL-47 $\left(\mathrm{V}^{\mathrm{IV}}\right)^{11}$ and MIL-53(Cr $)^{22}$ with one peak centered around $180^{\circ}$; the situation differs for the CP form with two contributions at $120^{\circ}$ and $160^{\circ}$ significantly down-shifted compared to the other analogues $\left(130^{\circ}\right.$ and $\left.180^{\circ}\right) .{ }^{11,22}$ Another significant change is the mean distance $(D)$ separating the phenyl rings which is much shorter in the $\mathrm{CP}$ form of $\mathrm{Al}$ $(3.29 \AA)$ vs. $\mathrm{Cr}$ and $\mathrm{V}^{\mathrm{IV}}$ (3.90 ̊̊) (Fig. 1 and Fig. S9, ESI $\dagger$ ), consistent with a more contracted simulated unit cell volume $\left(\sim 820 \AA^{3}\right.$ vs. $931 \AA^{3}$ and $950 \AA^{3}$ for $\mathrm{Cr}^{22}$ and $\mathrm{V}^{\mathrm{IV} 11}$ respectively). The resulting stronger $\pi-\pi$ packing interaction might contribute to a higher stabilization of the $\mathrm{Al} \mathrm{CP}$ structure. Both geometric features suggest that this structure is characterized by a deep potential energy well which prevents its re-opening. This was unambiguously confirmed by performing a computational scan in which the energy at $0 \mathrm{~K}$ and free energy at $300 \mathrm{~K}$ were calculated as a function of the unit cell volume (Fig. S11 and $\mathrm{S} 12, \mathrm{ESI}+$ ). Both energy profiles indeed revealed a deeply bound closed pore with large energy differences between the LP and the $\mathrm{NP}$ forms of 25 and $15 \mathrm{~kJ} \mathrm{~mol}^{-1}$ at $0 \mathrm{~K}$ and $300 \mathrm{~K}$ respectively, similar to the value previously reported by DFT calculations. ${ }^{23}$

In summary, the combination of characterization tools and modelling evidences that compared to its $\mathrm{Cr}^{-}$and $\mathrm{V}^{\mathrm{IV}}$ analogues, MIL-53(Al) shows the peculiarity to undergo an irreversible pressure induced structural transformation while maintaining almost the same unit cell volume change ( $\sim 35 \%)$. This suggests that complementary to the potential application of MIL-53(Cr) and MIL-47 $\left(\mathrm{V}^{\mathrm{IV}}\right)$ as nano-dampers, the Al-solid is able to irreversibly absorb the mechanical energy and can be potentially envisaged as a shock absorber. Moreover, while its mechanical energy storage performance of $\sim 6.6 \mathrm{~J} \mathrm{~g}^{-1}$ is lower than those previously pointed out for the $-\mathrm{Cr}\left(\sim 14 \mathrm{~J} \mathrm{~g}^{-1}\right)$ and $-\mathrm{V}^{\mathrm{IV}}$ $\left(\sim 33 \mathrm{~J} \mathrm{~g}^{-1}\right)$ analogues, it still remains within the same range compared to those observed for the mesoporous silica solids. ${ }^{2,3}$ This is the first experimental study which establishes that tuning the chemical features of the MOF framework allows a drastic modulation of its mechanical properties which paves the way towards the design of novel MOFs with targeted mechanical energy storage abilities.

The authors would like to thank the ANR "MODS" (ANR-12BS10-0005), the FWO, Ghent University (BOF) and ERC grant 240483. Computational resources were provided by Cines and Ghent University. G.M. thanks the Institut Universitaire de France for its support.

\section{Notes and references}

1 V. Eroshenko, R. C. Regis, M. Soulard and J. Patarin, J. Am. Chem. Soc., 2001, 123, 8129.

2 B. Lefevre, A. Saugey, J. L. Barrat, L. Bocquet, E. Charlaix, P. F. Gobin and G. Vigier, J. Chem. Phys., 2004, 120, 4927.

3 N. Gokulakrishnan, J. Parmentier, M. Trzpit, L. Vonna, J. L. Paillaud and M. Soulard, J. Nanosci. Nanotechnol., 2013, 13, 2847.

4 J. R. Li, J. Sculley and H. C. Zhou, Chem. Rev., 2011, 112, 869.

5 J. Gascon, A. Corma, F. Kapteijn and F. Llabrés i Xamena, ACS Catal., 2014, 4, 361

6 P. Horcajada, R. Gref, T. Baati, P. K. Allan, G. Maurin, P. Couvreur, G. Férey, R. E. Morris and C. Serre, Chem. Rev., 2011, 112, 1232.

7 T. D. Bennett, P. J. Saines, D. A. Keen, J. C. Tan and A. K. Cheetham, Chem. - Eur. J., 2013, 19, 7049.

8 P. Serra-Crespo, E. Stavitski, F. Kapteijn and J. Gascon, RSC Adv., 2012, 2, 5051.

9 K. W. Chapman, G. J. Halder and P. J. Chupas, J. Am. Chem. Soc., 2008, 130, 10524.

10 I. Beurroies, M. Boulhout, P. L. Llewellyn, B. Kuchta, G. Férey, C. Serre and R. Denoyel, Angew. Chem., Int. Ed., 2010, 49, 7526.

11 P. G. Yot, Q. Ma, J. Haines, Q. Yang, A. Ghoufi, T. Devic, C. Serre, V. Dmitriev, G. Férey, C. Zhong and G. Maurin, Chem. Sci., 2012, 3, 1100.

12 A. Ghoufi, A. Subercaze, Q. Ma, P. G. Yot, Y. Ke, I. Puente Orench, T. Devic, V. Guillerm, C. Zhong, C. Serre, G. Férey and G. Maurin, J. Phys. Chem. C, 2012, 116, 13289.

13 Q. Ma, Q. Yang, A. Ghoufi, M. Lei, G. Férey, C. Zhong and G. Maurin, J. Mater. Chem. A, 2014, 2, 99691.

14 F. Millange, N. Guillou, R. I. Walton, J. M. Greneche, I. Margiolaki and G. Férey, Chem. Commun., 2008, 39, 4732.

15 Y. Liu, J.-H. Her, A. Dailly, A. J. Ramirez-Cuesta, D. A. Neumann and C. M. Brown, J. Am. Chem. Soc., 2008, 130, 11813.

16 S. Devautour-Vinot, G. Maurin, F. Henn, C. Serre, T. Devic and G. Férey, Chem. Commun., 2009, 39, 2733.

17 T. Loiseau, C. Serre, C. Huguenard, G. Fink, F. Taulelle, M. Henry, T. Bataille and G. Férey, Chem. - Eur. J., 2004, 10, 1373.

18 P. Serra-Crespo, A. Dikhtiarenko, E. Stavitski, J. Juan-Alcañiz, F. Kapteijn, F.-X. Coudert and J. Gascon, CrystEngComm, 2014, DOI: $10.1039 /$ C4CE00436A.

19 A. V. Neimark, F. X. Coudert, C. Triguero, A. Boutin, A. Fuchs, A. Beurroies and R. Denoyel, Langmuir, 2011, 27, 4734.

20 Q. Ma, Q. Yang, A. Ghoufi, G. Férey, C. Zhong and G. Maurin, Dalton Trans., 2012, 41, 3915.

21 L. Vanduyfhuys, T. Verstraelen, M. Vandichel, M. Waroquier and V. Van Speybroeck, J. Chem. Theory Comput., 2012, 8, 3217.

22 F. Salles, A. Ghoufi, G. Maurin, R. G. Bell, C. Mellot-Draznieks and G. Férey, Angew. Chem., Int. Ed., 2008, 47, 8487.

23 A. M. Walker, B. Civalleri, B. Slater, C. Mellot-Draznieks, F. Corà, C. M. Zicovich-Wilson, G. Román-Pérez, J. M. Soler and J. D. Gale, Angew. Chem., Int. Ed., 2010, 49, 7501. 